\title{
Urgences
}

\section{Rocaille : octobre}

\section{Monique Grandmangin}

Numéro 16, mars 1987

D.G. Jones : d'un texte, d'autres

URI : https://id.erudit.org/iderudit/025391ar

DOI : https://doi.org/10.7202/025391ar

Aller au sommaire du numéro

Éditeur(s)

Urgences

ISSN

0226-9554 (imprimé)

1927-3924 (numérique)

Découvrir la revue

Citer ce document

Grandmangin, M. (1987). Rocaille : octobre. Urgences, (16), 56-57. https://doi.org/10.7202/025391ar d'utilisation que vous pouvez consulter en ligne.

https://apropos.erudit.org/fr/usagers/politique-dutilisation/ 


\section{Monique Grandmangin ROCAILLE: OCTOBRE}

Sous la pluie, ces ombres tombent en ruine: c'est le tombeau des fleurs

les teintes réunies

des feuilles mortes. Les pierres pourtant $y$ fleurissent

comme un cénacle de tomes où se poursuit le discours des disparus

De plus en plus, j'ai des pierres plein la bouche et les os de mes collègues

me rappellent les fleurs

Est-ce, ce fouillis, le paradis ou Angkor Vat

ou, la nuit, les tours grises

de la ville? Ni mort

ni vivant

ni même humain. Sous la pluie j'y passe, dans le sombre. C'est une floraison de runes 
Chaque printemps depuis bientôt quinze ans, je m'occupe d'embellir cette rocaille. Je ne croyais pas devoir aussi la traduire! Qu'en est-il? Il suffit de dire que ses dimensions sont plutôt restreintes et que les plantes, annuelles et vivaces, cultivées ou sauvages, se partagent l'espace entre ces vieilles pierres où s'accrochent la mousse et le lichen. Certaines proviennent de la région, d'autres de loin - de l'île Bonaventure par exemple - et chacune a été choisie avec soin par Douglas lui-même. Toutes sont désormais bien établies dans ce coin humide de l'Estrie, comme notre poète d'ailleurs, qui longe cette rocaille en se rendant à son refuge (sa «cabin" comme il dit) pour composer en paix.

L'intimité qui me lie à ce jardin a donc inspiré ma traduction de «Rock Garden: October»: dépouillée, concise, très simple finalement. Incapable de trouver une solution valable à "ruin/rune», j'ai dû me rabattre sur les assonances et les allitérations. Aussi, ai-je cru bon d'éliminer la plupart des «it is» que je rends par le présentatif "c'est» en dépit du pluriel au début de la deuxième strophe. Le «Still» de cette même strophe m'a fait hésiter; malgré les trois interprétations possibles "pourtant", "tranquille» et "continuer de " - j'ai fini par opter pour la première, la plus évidente, il me semble. Nous ne perdons ainsi qu'une seule nuance en français grâce à ufleurissent" (dans le sens de s'épanouir) dont l'aspect est duratif. Par ailleurs, le choix de "cénacle» pour rendre "gathering" m'a été inspiré par le contexte: une forme d' "animisme" qui me semblait approprié. Et finalement le "darkly», qui fait écho à la citation biblique ("Through a glass darkly»), ne pouvait se rendre par «d'une manière confuse» comme dans certaines versions françaises de la Bible. C'est donc au titre d'un recueil de Fernand Ouellette (Dans le sombre) que je suis redevable. Selon moi, tout en situant le moment du jour, ces trois mots évoquent les accents élégiaques de «Rock Garden». Je peux d'ailleurs vous assurer que notre poète, D.G. Jones, n'a pas sombré davantage depuis... 